\title{
Multiple S-isotopic evidence for episodic shoaling of anoxic water during Late Permian mass extinction
}

\author{
Yanan Shen ${ }^{1}$ James Farquhar², Hua Zhang ${ }^{3}$, Andrew Masterson², Tonggang Zhang ${ }^{1} \&$ Boswell A. Wing ${ }^{4}$
}

Global fossil data show that profound biodiversity loss preceded the final catastrophe that killed nearly $90 \%$ marine species on a global scale at the end of the Permian. Many hypotheses have been proposed to explain this extinction and yet still remain greatly debated. Here, we report analyses of all four sulphur isotopes $\left({ }^{32} \mathrm{~S},{ }^{33} \mathrm{~S},{ }^{34} \mathrm{~S}\right.$ and $\left.{ }^{36} \mathrm{~S}\right)$ for pyrites in sedimentary rocks from the Meishan section in South China. We observe a sulphur isotope signal (negative $\delta^{34} \mathrm{~S}$ with negative $\Delta^{33} \mathrm{~S}$ ) that may have resulted from limitation of sulphate supply, which may be linked to a near shutdown of bioturbation during shoaling of anoxic water. These results indicate that episodic shoaling of anoxic water may have contributed to the profound biodiversity crisis before the final catastrophe. Our data suggest a prolonged deterioration of oceanic environments during the Late Permian mass extinction. 
T he end-Permian extinction has been regarded as the most severe of all mass extinctions in the Phanerozoic ${ }^{1-3}$. Exterrestrial impact, the eruption of Siberian basalts, oceanic anoxia, hydrogen sulphide poisoning or perhaps combination of these has been proposed to explain this extinction ${ }^{1-7}$. However, the cause of biodiversity crisis before the final catastrophe has received little attention. To explore palaeoceanographic changes and their contributions to the Late Permian mass extinction, we analysed all four S-isotopic compositions of pyrites from the Meishan section in South China.

The Meishan section arguably provides the most detailed records of the Latest Permian biotic crisis ${ }^{1,8,9}$. A profound loss of marine fauna, including most fusulinids and ammonoids and many brachipods, is observed below Bed 25 at Meishan ${ }^{8-10}$. Fossil records suggest that the onset of biodiversity loss probably began during deposition of Bed 22, with an extinction rate of $<33 \%$ (ref. 8-10; Em in Fig. 1), and continued until the end-Permian extinction event, which is preserved in Beds 25-26 (E1 in Fig. 1). At Meishan, the end-Permian extinction preserved by Beds $25-26$ is estimated to have marked a loss of $94 \%$ of marine species within $<0.5$ million years $^{8,11}$. Recent biomarker data also suggest a separate, later episode of extinction occurring during deposition of Bed 28 (ref. 12; E2 in Fig. 1). The picture that has emerged may not be of a singular event but rather of a series of events, the cause(s) of which is currently the most debated of the mass extinctions.

Among all extinction events at Meishan (Em-E2), the end-Permian extinction at Beds 25-26 has been examined in greatest detail.
The catastrophic extinction event (E1 in Fig. 1) coincides with many geochemical anomalies, such as a negative $\delta^{13} \mathrm{C}$ excursion ${ }^{8,12,13}$, the presence of a relatively large fractionation of $45.3 \%$ o between pyrite and carbonate-associated sulphate ${ }^{14}$, the possible existence of fullerenes in the boundary sediments ${ }^{15}$ (but see refs. 16,17), negative $\delta^{34} S$ shift for carbonate-associated sulphate ${ }^{18}$ (but see ref. 19) and the occurrence of isorenieratane $e^{20-23}$ (but see ref. 24). Hypotheses about the cause of extinction have been proposed on the basis of these records and include impact, chemocline upward excursion, photic zone euxinia (anoxic and sulphidic water column conditions) or some combinations of these $\mathrm{e}^{1}$. It remains unclear which of these hypotheses are valid and the nature of their connection to the profound biodiversity loss that preceded the end-Permian extinction.

In this study, we report multiple S-isotopic analysis of pyrites from the Meishan section. We discover a sulphur isotope signal (negative $\delta^{34} S$ with negative $\Delta^{33} S$ ) that suggests episodes when porewater sulphate was converted nearly quantitatively to sulphide. This S-isotopic signal may have resulted from mixing of pyrites and suggests that shoaling of deep anoxic water may have contributed to the significant biodiversity loss before the final catastrophic extinction.

\section{Results}

Sampling of the Meishan section. Our samples were collected from the Meishan section in South China, which is the Global Stratotype Section and Point (GSSP) for the Permian-Triassic boundary ${ }^{8,9}$. a

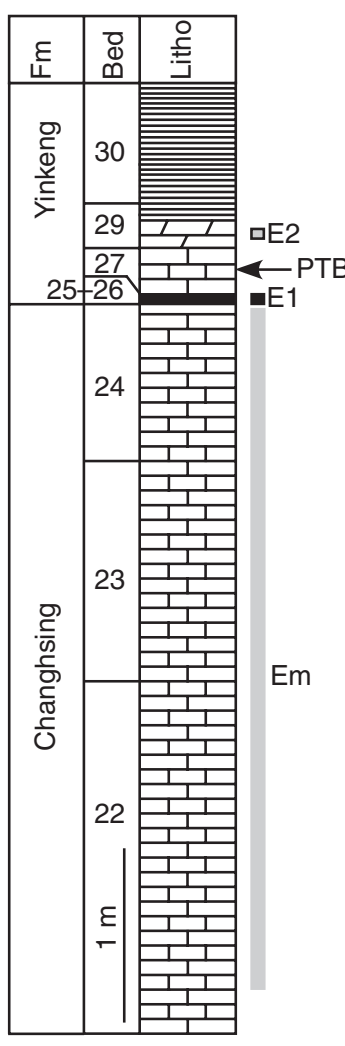

b $-36$

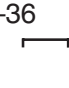

0 0 0000

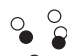

$\circ$ 0

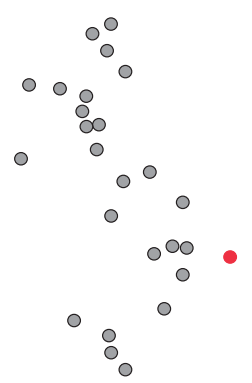

$\delta^{34} S$

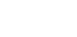

$\infty$
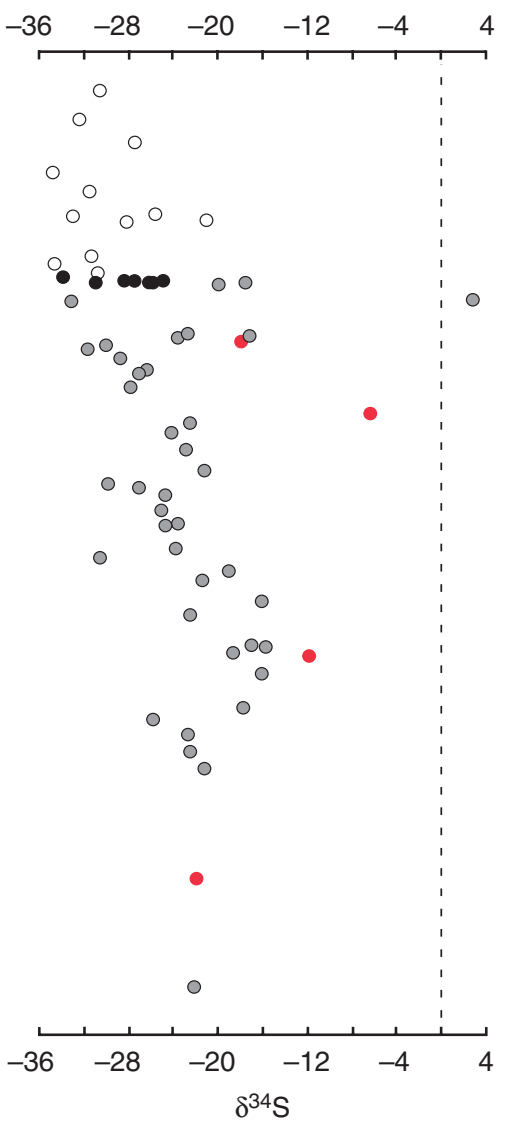

Limestone

다 Dolostone c
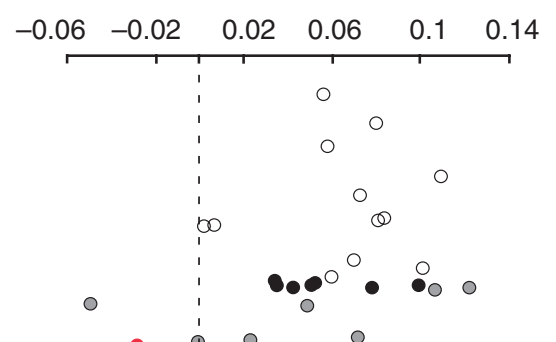

$\bullet$
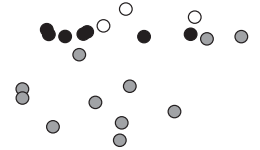

$\begin{array}{l:ll}1 & 0 & \\ & 0 & 0\end{array}$
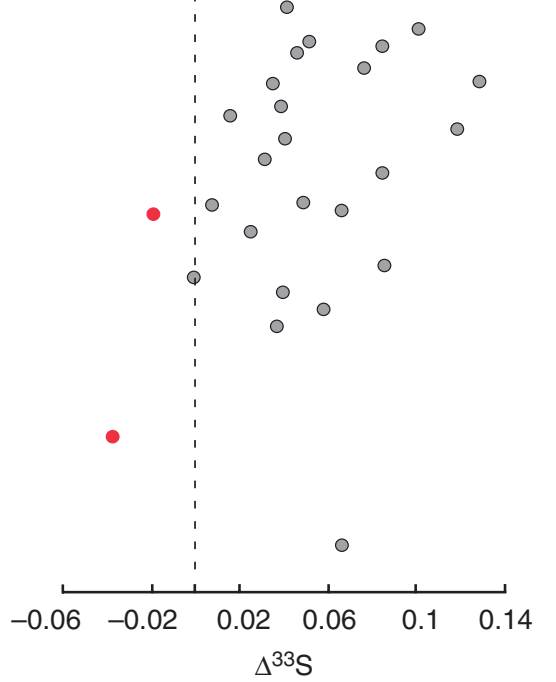

Black shale

Figure 1 | The Permian-Triassic stratigraphy and sulphur isotopic data at Meishan. (a) Stratigraphy of the Permian-Triassic boundary (PTB) and extinction events Em, E1 and E2. Note that E2 corresponds to Bed 28 (not shown). (b) Sulphur isotopic compositions ( $\delta^{34} \mathrm{~S}$ ) of pyrites at Meishan. Grey filled circles are Beds 22-24, black circles are Beds 25-26 and open circles are Beds 27-30. (c) Sulphur isotopic compositions ( $\Delta^{33} \mathrm{~S}$ ) of pyrites at Meishan. Red circles indicate negative $\delta^{34} \mathrm{~S}$ and $\Delta^{33} \mathrm{~S}$ values. 
We sampled Beds 22-30 of the Late Permian Changhsing Formation to Early Triassic Yinkeng Formation that recorded the detailed patterns of the Late Permian extinction (Fig. 1). Beds 22-24 comprises limestone. Beds 25 and 26 were named 'event beds', which were usually $\sim 1-2 \mathrm{~cm}$ thick, among which bed 25 was gray-green clay and bed 26 was black clay. Zircons from ash layers in Beds 25-26 yielded a U-Pb age of $251.4 \pm 0.3 \mathrm{Ma}$ (ref. 11). Bed 27 consists of argillaceous wackstone and dolostone within which the first appearance datum of conodont Hindeodus parvus was reported ( $10 \mathrm{~cm}$ above Bed 25$)$, marking the Permian-Triassic boundary ${ }^{9}$. Bed 28 is gray-green ash clay of $\sim 0.5 \mathrm{~cm}$ thickness from which a U-Pb age of $250.7 \pm 0.3 \mathrm{Ma}$ of zircon was obtained ${ }^{11}$. The lower part of Bed 29 is dominated by carbonate and overlain by organic-rich mudstone up to Bed 30 (Fig. 1).

S-isotopic data before the end-Permian extinction. We report data for all four S-isotopes $\left({ }^{32} \mathrm{~S},{ }^{33} \mathrm{~S},{ }^{34} \mathrm{~S}\right.$ and $\left.{ }^{36} \mathrm{~S}\right)$ of pyrites from the Meishan section, which is the first multiple S-isotopic study on the Permian-Triassic mass extinctions. Sulphur isotope data are presented using delta notation $\delta^{34} \mathrm{~S}=\left[\left({ }^{34} \mathrm{~S} /{ }^{32} \mathrm{~S}\right)_{\text {sample }} /\left({ }^{34} \mathrm{~S} /{ }^{32} \mathrm{~S}\right)_{\text {reference }}-1\right]$ and capital delta notation $\Delta^{33} \mathrm{~S}=\left[\left({ }^{33} \mathrm{~S} /{ }^{22} \mathrm{~S}\right)_{\text {sample }} /\left({ }^{33} \mathrm{~S} /{ }^{32} \mathrm{~S}\right)_{\text {reference }}-\left(\left({ }^{34} \mathrm{~S} /\right.\right.\right.$ $\left.\left.\left.{ }^{32} \mathrm{~S}\right)_{\text {sample }} /\left({ }^{34} \mathrm{~S} /{ }^{32} \mathrm{~S}\right)_{\text {reference }}\right)^{0.515}\right]$. Capital delta and delta values are given in units of per mil (\%o). Small deviations for $\Delta^{33} S$ and $\Delta^{36} S$ can be used to examine the way in which sulphur is cycled in biological and biogeochemical systems ${ }^{25-29}$. Figures 1 and 2 (full analytical data available as Supplementary Data 1 ) present the $\delta^{34} S$ and $\Delta^{33} S$ data for pyrites from the Meishan section.

The $\delta^{34} S$ of pyrites in Beds 22-24 of the Changhsing Formation show significant negative values ranging from -6.26 to $-33.0 \%$ o (mostly -17 to $-31 \%$ ) except one positive value of $2.88 \%$ in the uppermost part of Bed 24 (Fig. 1). $\Delta^{33}$ S values of pyrites from Bed 22 to Bed 24 range from 0.123 to -0.037 . For most of the Changhsing pyrites, they show negative $\delta^{34}$ S values and positive $\Delta^{33}$ Svalues (Fig. $2 \mathrm{~b}$, quadrant II). A positive $\delta^{34} S$ value of $2.88 \%$ with negative $\Delta^{33} S$ value of -0.049 for pyrite is seen in the uppermost part of Bed 24 (Fig. 2b, quadrant IV). Negative $\delta^{34} S$ values and negative $\Delta^{33} \mathrm{~S}$ values are present for Beds 22-24 (Fig. 2b, quadrant III) and they occur scattered through the Changhsing Formation (Fig. 1).

S-isotopic data during and after the end-Permian extinction. The $\delta^{34} S$ of pyrites in Beds 25-26, where the final catastrophic extinction occurred, exhibit negative values ranging from -33.72 to $-24.78 \%$, with positive $\Delta^{33} \mathrm{~S}$ values ranging from 0.034 to 0.010 (Fig. 2b, quadrant II). Above the extinction event at Beds 25-26, pyrites from Bed 27 to Bed 30 of the Yinkeng Formation are characterized by significantly negative $\delta^{34} S$ values from -21.0 to $-34.7 \%$ o and $\Delta^{33} \mathrm{~S}$ values from 0 to 0.101 (Fig. 2b, quadrant II). We observe no pyrites from Bed 25 to Bed 30 of the Yinkeng Formation showing negative $\delta^{34} S$ and negative $\Delta^{33} S$.

\section{Discussion}

A context for interpreting these observations is presented in Figure 2, in which we illustrate the predictions of a steady-state global sulphur cycle model similar to that described by Johnston et al..$^{30}$. The fields in this figure represent the composition of the global average of buried pyrite and do not account for heterogeneity of sedimentary pyrite on basinal or regional scale. The fields of buried pyrite are situated in quadrant II (negative $\delta^{34} S$ and positive $\Delta^{33} S$ ), and its location is a consequence of the fractionation relationships produced by sulphate reduction, disproportionation of sulphur intermediate compounds and the conservation of mass in the sulphur cycle $^{31}$. This pyrite may be formed in water columns or in sediments (so-called syngenetic pyrite or diagenetic pyrite), and the negative $\delta^{34} \mathrm{~S}$ and positive $\Delta^{33} \mathrm{~S}$ values reflect lower degrees of sulphate reduction in open-system environments, and pyrite with this composition is typical in modern sediments and geological rock record ${ }^{30,32,33}$. Observation of pyrite that does not get plotted in this field reflects
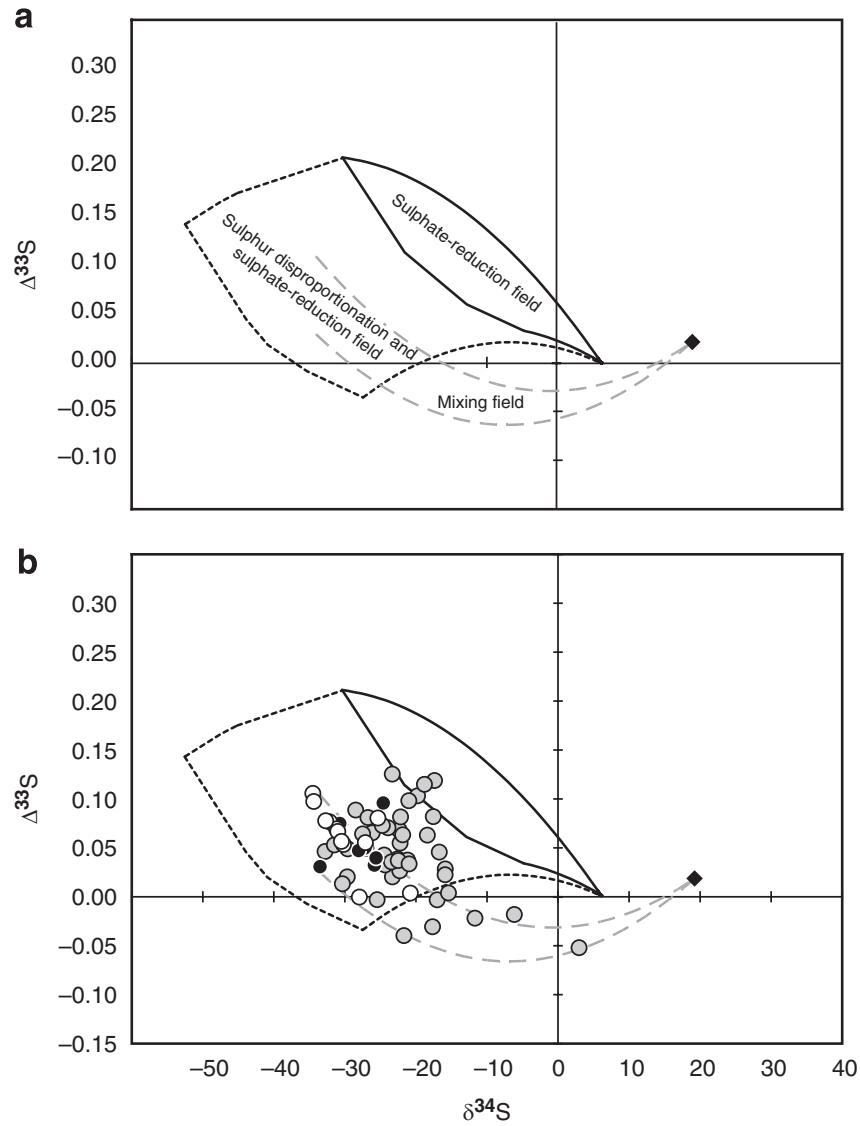

Figure 2 | Plot of $\Delta^{\mathbf{3}} \mathbf{S}$ against $\boldsymbol{\delta}^{\mathbf{3 4}} \mathbf{S}$. (a) Plot of $\Delta^{33} S$ against $\delta^{34}$ S illustrating fields of data produced by sulphate reduction only, sulphate reduction and disproportionation, and mixing between pyrite produced by near quantitative reduction of sulphate and by a combination of sulphate reduction and disproportionation. (b) Plot of $\Delta^{33} S$ against $\delta^{34} S$ for data from Meishan pyrites illustrating data that get plotted in fields of sulphate reduction and disproportionation, and also mixing between pyrite produced by near quantitative reduction of sulphate and by a combination of sulphate reduction and disproportionation. Grey filled circles are Beds 22-24, black circles are Beds 25-26 and open circles are Beds 27-30.

local and regional processes that operate in the sulphur cycle. For example, diagenetic pyrite formed in normal marine sediments with positive $\delta^{34} S$ and either positive or negative $\Delta^{33} S$ (quadrant I and IV) reflects high degrees of sulphate reduction or an approach to quantitative reduction of sulphate $e^{29,32}$. Pyrite with negative $\delta^{34} S$ and negative $\Delta^{33}$ Svalues in quadrant III cannot, however, be accounted for neither by sulphate reduction or sulphur disproportionation in typical stable diagenetic systems nor by nearly quantitative reduction of sulphate that acts alone. Pyrite with negative $\delta^{34} S$ and negative $\Delta^{33} S$ (quadrant III) suggests mixing of sulphur from sulphide sources with sulphur from nearly quantitative reduction of sulphate ${ }^{29,32}$. This latter isotopic signature is present in some pyrites from Meishan, which temporally correlate with profound biodiversity loss (Fig. 2) and provide new insights into palaeoceanographic changes during the Late Permain extinction processes.

The majority of pyrite analyses occupy quadrant II, showing significant negative $\delta^{34} S$ values and positive $\Delta^{33} S$ values observed from the Changshing and Yinkeng formations (Fig. 2b) and are consistent with observations from other diagenetic settings in both euxinic and oxic environments ${ }^{33}$. One analysis occupies quadrant IV $(\sim 9 \mathrm{~cm}$ below Bed 25), showing a positive $\delta^{34} \mathrm{~S}$ of $2.88 \%$ and negative $\Delta^{33} \mathrm{~S}$ of -0.049 (Fig. 2b). This isotopic composition has more negative 

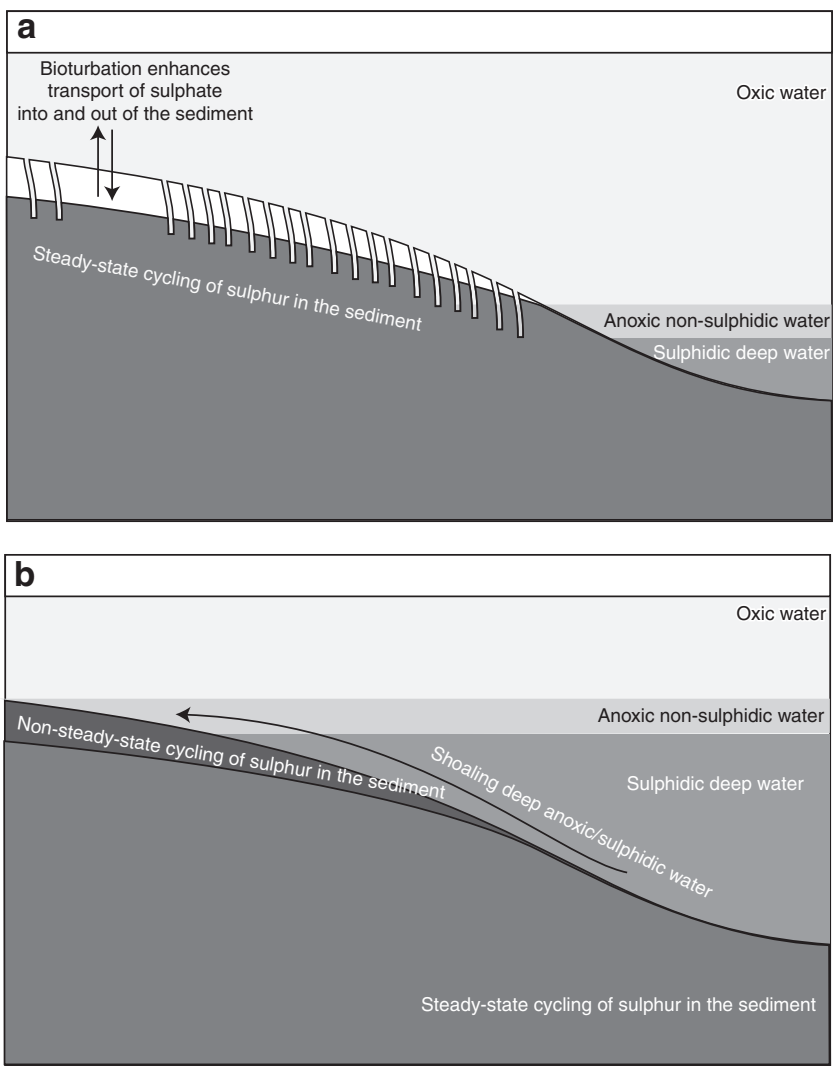

Figure 3 | A cartoon representing the sulphur cycle associated with the shoaling deep anoxic water during the Latest Permian. (a) Sulphur cycle under typical steady-state conditions in which bioturbation aerates shallow sediments and promotes transport of sulphate into and out of the sediments. (b) Sulphur cycle associated with shoaling of deep anoxic water in which bioturbation shuts down, limiting transport of sulphate within sediments and exchange between sediment pore water sulphate and oceanic sulphate pools. High organic content in the sediments promotes nearly quantitative sulphate reduction, resulting in non-steady-state conditions and formation of pyrites with negative $\delta^{34} S$ and negative $\Delta^{33} S$ values as seen in Figures 1 and 2.

$\delta^{34} S$ and $\Delta^{33} S$ than estimates of contemporaneous seawater ${ }^{34}$, and it suggests mixing between an end-member with little or no isotopic fractionation during sulphate reduction or nearly quantitative reduction of sulphate. Such mixing can occur when sulphate-reduction rates are enhanced relative to the supply of porewater sulphate (Fig. 2). We suggest that the four analyses with negative $\delta^{34} S$ and negative $\Delta^{33} \mathrm{~S}$ values located in quadrant III (Fig. 2b) reflect a similar situation. These isotopic characteristics are present episodically from Beds 22 to 24, and suggest mixing of pyrite produced in two different settings, one in which sulphate is nearly quantitatively reduced and the other in which sulphate reduction and pyrite formation occurs with significant exchange between porewater sulphate in sediment and sulphate in the overlying water column.

The mixing of pyrite observed from Meishan may be indicative of shoaling of anoxic deep water before the end-Permian mass extinction in Beds 25-26. A cartoon that describes the principal features of this hypothesis is presented in Figure 3, and envisions a situation similar to that observed in the Black Sea where oxic waters overly but is separated from a deep water euxinic pool by $\mathrm{Fe}^{2+}$-rich nonsulphidic, anoxic waters (Fig. 3a). This scenario is based on deep-water column euxinia during the latest Permian that has been well documented ${ }^{2,5,14,35,36}$. When anoxic water shoal, the sulphur cycle within sediments, formerly in the oxic zone, will change from a system with effective transport of sulphate into and out of the sediment (Fig. 3b) to a system in which bioturbation does not play a significant role, and effective exchange of sulphate between the sediment porewater and the overlying water column would be suppressed.

When anoxic deep water shoal into the oxic zone, oxidation of sulphide in the sediment will be suppressed and there is a potential for delivery of iron to the sediment from the anoxic water column (Fig. 3b). The sediments in which sulphate reduction is initiated may possess significant organic electron donors for sulphate reduction, allowing for high sulphate-reduction rates that may outpace the sulphate supply by diffusion from the overlying water column, thus contributing a sulphur component that occupies quadrant III and IV. Shoaling of anoxic water would have killed marine animals, limiting bioturbation, transport of sulphate from overlying seawater into the sediments and sulphide oxidation. Addition of pyrite formed during such an event to pyrite already present in the sediments would therefore provide an explanation for our observations of pyrite that get plotted in quadrant IV and pyrite that get plotted in quadrant III (Beds 22-24; Fig. 2).

The negative $\delta^{34} S$ and negative $\Delta^{33} S$ values at Beds $22-24$ from Meishan therefore provide a geochemical signal that links episodic incursion of anoxic water with extermination of bioturbating organisms, suppression of sulphate transport and enhanced sulphate reduction. The temporal coincidence between shoaling of anoxic water and the profound biodiversity loss suggests that episodic incursion of anoxic water into the shallower water may have contributed to the biodiversity crisis that preceded the endPermian extinction. Interestingly, we observe no negative $\delta^{34} S$ and negative $\Delta^{33} S$ values at Beds 25-26 that recorded the final catastrophic extinction. This may be attributable to preservation biases at Meishan but it may also reflect a stable diagenetic system and imply that the cause of the end-Permian extinction was different from that of the biodiversity loss before it. Further isotopic studies carried out in the framework of biostratigraphy should clarify the relationships between environmental changes and the Late Permian mass extinction.

\section{Methods}

Pyrite extraction. In this study, pyrite sulphur from rock samples was extracted using chromium reduction and converted to silver sulphide. During this procedure, the product $\mathrm{H}_{2} \mathrm{~S}$ was carried by nitrogen gas through a condenser and a bubbler filled with milli-Q water, and collected as zinc sulphide by reaction with a slightly acidic $\mathrm{Zn}$-acetate solution. The zinc sulphide was made to react with silver nitrate to yield silver sulphide, which was collected by centrifugation and washed with successive rinses of milli-Q water, ammonium hydroxide solution and milli-Q water.

Sulphur isotopic analysis. Silver sulphide $\left(\mathrm{Ag}_{2} \mathrm{~S}\right)$ was converted to $\mathrm{SF}_{6}$ by a fluorination reaction with a fivefold excess of $\mathrm{F}_{2}$ at $250{ }^{\circ} \mathrm{C}$ for $8 \mathrm{~h}$ in a Ni reaction vessel. After the reaction, product $\mathrm{SF}_{6}$ was condensed from the residual $\mathrm{F}_{2}$ into a liquidnitrogen-cooled trap $\left(-177^{\circ} \mathrm{C}\right)$. The $\mathrm{F}_{2}$ was removed to another part of the manifold where it was passivated by reaction with hot $\mathrm{KBr}$. The $\mathrm{SF}_{6}$ was subsequently thawed to room temperature and then cooled to $-111^{\circ} \mathrm{C}$ to condense contaminants, such as trace $\mathrm{HF}$, before it was transferred to the injection loop of a gas chromatograph, which was cooled to $-177^{\circ} \mathrm{C}$. Gas chromatograph purification of $\mathrm{SF}_{6}$ was undertak en using a composite column consisting of a 1/8-inch diameter, 6 -foot lead column of $5 \mathrm{~A}$ molecular sieve, followed by a $1 / 8$-inch diameter, 12 -foot-long Haysep- $\mathrm{Q}^{\mathrm{m}}$ column. The He carrier flow was set at $20 \mathrm{ml} \mathrm{min}^{-1}$. The $\mathrm{SF}_{6}$ peak was registered on a thermal conductivity detector and then isolated by freezing into a liquid-nitrogencooled trap. The isotopic composition of the purified $\mathrm{SF}_{6}$ was determined by dualinlet gas-source mass spectrometry monitoring ion beams at $m / e$ of $127,128,129$ and 131, using a Thermo Finnigan MAT 253 gas source mass spectrometer.

One-sigma uncertainties on mass-dependent reference materials are better than $\pm 0.2 \%$ o, $\pm 0.01 \%$ ond $\pm 0.2 \%$ in $\delta^{34} S, \Delta^{33} S$ and $\Delta^{36}$ S, respectively. Uncertainties on the measurements reported here are estimated to be better than $\pm 0.2 \%$ o, $\pm 0.01 \%$ and $\pm 0.2 \%$. The results of our measurements are presented in Supplementary Data 1.

\section{References}

1. Erwin, D. H. Extinction: How Life on Earth Nearly Ended 250 Million Years Ago 296 (Princeton Univ. Press, 2006). 
2. Knoll, A. H., Bambach, R. K., Payne, J. L., Pruss, S. \& Fischer, W. W. Paleophysiology and end-Permian mass extinction. Earth Planet Sci. Lett. 256, 295-313 (2007).

3. Bottjer, D. J., Clapham, M. E., Fraiser, M. L. \& Powers, C. M. Understanding mechanisms for the end-Permian mass extinction and the protracted Early Triassic aftermath and recovery. GSA Today 18, 4-10 (2008).

4. Knoll, A. H., Bambach, R. K., Canfield, D. E. \& Grotzinger, J. P. Comparative earth history and Late Permian mass extinction. Science 273, 452-457 (1996).

5. Isozaki, Y. Permo-Triassic boundary superanoxia and stratified superocean: records from lost deep sea. Science 276, 235-238 (1997).

6. Kump, L. R., Pavlov, A. \& Arthur, M. A. Massive release of hydrogen sulphide to the surface ocean and atmosphere during intervals of oceanic anoxia. Geology 33, 397-400 (2005).

7. Payne, J. L. et al. Calcium isotope constraints on the end-Permian mass extinction. Proc. Natl Acad. Sci. USA 107, 8543-8548 (2010).

8. Jin, Y. G. et al. Pattern of marine mass extinction near the Permian-Triassic boundary in South China. Science 289, 432-436 (2000).

9. Yin, H., Zhang, K. X., Tong, J. N., Yang, Z. Y. \& Wu, S. B. The global stratotype section and point (GSSP) of the Permian-Triassic boundary. Episodes 24, 102-114 (2001).

10. Yin, H. et al. The prelude of the end-Permian mass extinction predates a postulated bolide impact. Int. J. Earth Sci. 96, 903-909 (2007).

11. Bowring, $\mathrm{S}$. A. et al. U/Pb Zircon geochronology and tempo of the endPermian mass extinction. Science 280, 1039-1045 (1998).

12. Xie, S., Pancost, R. D., Yin, H., Wang, H. \& Evershed, R. P. Two episodes of microbial change coupled with Permo/Triassic faunal mass extinction. Nature 434, 494-497 (2005).

13. Payne, J. L. et al. Large perturbations of the carbon cycle during recovery from the End-Permian extinction. Science 305, 506-509 (2004).

14. Riccardi, A. L., Arthur, M. A. \& Kump, L. R. Sulfur isotopic evidence for chemocline upward excursions during the end-Permian mass extinction. Geochim. Cosmochim. Acta 70, 5740-5752 (2006)

15. Becker, L., Poreda, R. J., Hunt, A. G., Bunch, T. E. \& Rampino, M. Impact event at the Permian-Triassic boundary: evidence from extraterrestrial noble gases in fullerenes. Science 291, 1530-1533 (2001)

16. Farley, K. A. \& Mukhopadhyay, S. An extraterrestrial impact at the PermianTriassic boundary? Science 293, 2343 (2001).

17. Isozaki, Y. An extraterrestrial impact at the Permian-Triassic boundary? Science 293, 2343 (2001).

18. Kaiho, K. et al. End-Permian catastrophe by a bolide impact: evidence of a gigantic release of sulfur from the mantle. Geology 29, 815-818 (2001)

19. Koeberl, C., Gilmour, L., Reimold, W. U., Claeys, P. \& Ivanov, B. End-Permian catastrophe by bolide impact: evidence of a gigantic release of sulfur from the mantle: comment. Geology 30, 855-856 (2002).

20. Grice, K. et al. Photic zone euxinia during the Permian-Triassic superanoxic event. Science 307, 706-709 (2005).

21. Cao, C. Q. et al. Biogeochemical evidence for euxinic oceans and ecological disturbance presaging the end-Permian mass extinction event. Earth Planet Sci. Lett. 281, 188-201 (2009).

22. Nabbefeld, B. et al. An integrated biomarker, isotopic and palaeoenvironmental study through the Late Permian event at Lusitaniadalen, Spitsbergen. Earth Planet Sci. Lett. 291, 84-96 (2010a).

23. Nabbefeld, B. et al. Significance of $\delta D_{\text {kerogen }}, \delta^{13} C_{\text {kerogen }}$ and $\delta^{34} S_{\text {pyrite }}$ from several Permian/Triassic (P/Tr) sections. Earth Planet Sci. Lett. 295, 21-29 (2010).

24. Nielsen, J. K., Shen, Y., Piasecki, S. \& Stemmerik, L. No abrupt change in redox condition caused the end-Permian marine ecosystem collapse in the East Greenland Basin. Earth Planet Sci. Lett. 291, 32-38 (2010).
25. Farquhar, J. et al. Multiple sulphur isotopic interpretations of biosynthetic pathways: implications for biological signatures in the sulphur isotope record. Geobiology 1, 27-36 (2003).

26. Farquhar, J., Canfield, D. E., Masterson, A., Bao, H. \& Johnston, D. T. Sulfur and oxygen isotope study of sulfate reduction in experiments with natural populations from Fœllestrand, Denmark. Geochim. Cosmochim. Acta. 72, 2805-2821 (2008).

27. Johnston, D. T. et al. Multiple sulphur isotope fractionations in biological systems: a case study with sulphate reducers and sulphur disproportionators. Am. J. Sci. 305, 645-660 (2005).

28. Johnston, D. T., Farquhar, J. \& Canfield, D. E. Sulfur isotope insights into microbial sulfate reduction: when microbes meet models. Geochim. Cosmochim. Acta. 71, 3929-3947 (2007)

29. Ono, S., Wing, B. A., Johnston, D., Farquhar, J. \& Rumble, D. Mass-dependent fractionation of quadruple stable sulfur isotope system as a new tracer of sulfur biogeochemical cycles. Geochim. Cosmochim. Acta. 70, 2238-2252 (2006).

30. Johnston, D. T. et al. Active microbial sulfur disproportionation in the Mesoproterozoic. Science 310, 1477-1479 (2005).

31. Farquhar, J., Johnston, D. T. \& Wing, B. A. Implications of conservation of mass effects on mass-dependent isotopic fractionation: influence of network structure on sulfur isotope phase space of dissimilatory sulfate reduction. Geochim. Cosmochim. Acta. 71, 5862-5875 (2007).

32. Johnston, D. T. et al. Evolution of the oceanic sulfur cycle at the end of the Paleoproterozoic. Geochim. Cosmochim. Acta. 70, 5723-5739 (2006).

33. Johnston, D. T., Farquhar, J., Habicht, K. S. \& Canfield, D. E. Sulphur isotopes and the search for life: strategies for identifying sulphur metabolisms in the rock record. Geobiology 6, 425-435 (2008).

34. Wu, N. P., Farquhar, J., Strauss, H., Kim, S.- T. \& Canfield, D. E. Evaluating the S-isotope fractionation associated with Phanerozoic pyrite burial. Geochim. Cosmochim. Acta. 74, 2053-2071 (2010).

35. Nielsen, J. K. \& Shen, Y. Evidence for sulfidic deep water during the Late Permian in the East Greenland Basin. Geology 32, 1037-1040 (2004)

36. Grasby, S. E. \& Beauchamp, B. Latest Permian to Early Triassic basin-to-shelf anoxia in the Sverdrup Basin, Arctic Canada. Chem. Geol. 264, 232-246 (2009).

\section{Acknowledgments}

This study was supported by NNSFC (41025011, 40528004) (Y.S.), NNSFC (40702017)

(H.Z.), NNX07AK13G, NAI, the Guggenheim Foundation (J.F.) and NSERC (B.A.W.)

\section{Author contributions}

Y.S. conceived this study; A.M., H.Z., J.F. and Y.S. carried out the analyses and sampling; Y.S. and J.F. wrote the paper; and all authors provided intellectual input.

\section{Additional information}

Supplementary Information accompanies this paper at http://www.nature.com/ naturecommunications

Competing financial interests: The authors declare no competing financial interests.

Reprints and permission information is available online at http://npg.nature.com/ reprintsandpermissions/

How to cite this article: Shen, Y. et al. Multiple S-isotopic evidence for episodic shoaling of anoxic water during Late Permian mass extinction. Nat. Commun. 2:210 doi: $10.1038 /$ ncomms1217 (2011)

License: This work is licensed under a Creative Commons Attribution-NonCommercialShare Alike 3.0 Unported License. To view a copy of this license, visit http:// creativecommons.org/licenses/by-nc-sa/3.0/ 